\title{
Role of calcium in the regulation of bone morphogenetic protein 2 , runt-related transcription factor 2 and Osterix in primary renal tubular epithelial cells by the vitamin $D$ receptor
}

\author{
ZHAOHUI JIA, SHAOGANG WANG, DENG HE, LEI CUI, YUCHAO LU, \\ HENGLONG HU, BAOLONG QIN and ZHENYU ZHAO
}

\begin{abstract}
Department of Urology, Tongji Hospital, Tongji Medical College, Huazhong University of Science and Technology, Wuhan, Hubei 430030, P.R. China
\end{abstract}

Received June 10, 2014; Accepted February 20, 2015

DOI: $10.3892 / \mathrm{mmr} .2015 .3568$

\begin{abstract}
The aim of the present study was to investigate the effect of $1,25(\mathrm{OH})_{2} \mathrm{D}_{3} /$ vitamin D receptor (VDR) and calcium on the expression levels of osteogenic factors in primary renal tubular epithelial cells (RTECs) using genetic hypercalciuric rats. The basal levels of osteogenic factors were detected in Sprague Dawley and genetic hypercalciuric rats. The gene and protein levels of bone morphogenetic protein 2 (BMP2), runt-related transcription factor 2 (Runx2) and osterix were detected in the RTECs transduced with Lenti-VDR-sh and were incubated with calcium. Using the o-cresolphthalein complexone method, the calcium levels of the primary RTECs cultured with Lenti-VDR-sh and with $1,25(\mathrm{OH})_{2} \mathrm{D}_{3}$ were assessed. The basal levels of BMP2, Runx2 and Osterix in the cells were significantly higher in the genetic hypercalciuric rats compared with the control rats. VDR knockdown in the RTECs reduced the expression levels of BMP2, Runx2 and Osterix. The calcium depositions in the primary RTECs were also decreased following exposure to Lenti-VDR-sh, but increased following treatment with $1,25(\mathrm{OH})_{2} \mathrm{D}_{3}$. The expression levels of BMP2, Runx2 and Osterix were markedly increased in the cells incubated with calcium compared with the cells treated with normal saline and the untreated cells. These findings indicated that osteogenic factors, including BMP2, Runx2 and Osterix may be important in renal stone formation in idiopathic hypercalciuria. VDR may mediate the increased expression levels of BMP2, Runx 2 and Osterix by positively regulating calcium levels in primary RTECs.
\end{abstract}

Correspondence to: Professor Shaogang Wang, Department of Urology, Tongji Hospital, Tongji Medical College, Huazhong University of Science and Technology, 1095 Jiefang Avenue, Wuhan, Hubei 430030, P.R. China

E-mail: sgwangtjm@163.com

Key words: idiopathic hypercalciuria, vitamin D receptor, bone morphogenetic protein 2 , runt-related transcription factor 2 , osterix

\section{Introduction}

Idiopathic hypercalciuria (IH), as a metabolic alteration of high prevalence, is considered a risk factor for urolithiasis. Several linkage studies of patients with calcium-containing urolithiasis and IH have indicated an association with the 12q12-14 chromosomal locus, which contains the vitamin D receptor (VDR) gene. In a study of 150 patients with nephrolithiasis from northern India, Relan (1) demonstrated that VDR genotypes appeared to correlate with increased calcium excretion in hypercalciuric nephrolithiasis. In 2004, Favus (2) observed that the peripheral blood monocyte VDR was two-fold greater in the male calcium oxalate stone formers with IH compared with controls. These indicated that elevated levels of the VDR may account for the excess urine calcium and kidney stone formation.

The link between urolithiasis and vascular disease is well documented. Vascular calcification is a cell osteogenic phenotype transition, which involves numerous osteogenic factors synthesized by vascular smooth muscle cells (VSMCs), including bone morphogenetic protein 2 (BMP2), runt-related transcription factor 2 (Runx2), alkaline phosphatase (ALP), type I collagen and osteocalcin, and are usually associated with the induction of bone formation (3-6). Therefore, osteogenic factors may assist in understanding kidney stone formation.

A colony of genetic hypercalciuric rats has been previously established (7). This rat model of hypercalciuria consistently excretes more calcium in urine and contains higher levels of VDR in the duodenum and kidney compared with control rats $(7,8)$. In our previous study, several osteogenic factors, including BMP2, Runx2, Osterix and osteopontin, were found to be significantly higher in genetic hypercalciuric rat kidney tissue than in control rat tissue (9). Therefore, stone formation in kidney tissue may proceed in the same manner as bone formation, and this process may be regulated by VDR. However, the role of VDR and these osteogenic factors remains to be fully elucidated. The aim of the present study was to investigate the association between VDR, osteogenic factors and calcium and elucidate the regulatory mechanism of VDR in vitro using genetic hypercalciuric rats. 


\section{Materials and methods}

Genetic hypercalciuric rats. All animal procedures were approved by the ethics committee of Huazhong University of Science and Technology (Wuhan, China). Adult Sprague-Dawley (SD) rats (Experimental Animal Center, Tongji Medical College, Huazhong University of Science and Technology) were placed in individual metabolic cages and fed with $13 \mathrm{~g} / \mathrm{day}$ of a diet containing $1.2 \%$ calcium, $0.65 \%$ phosphorus, $0.43 \%$ chloride, $0.4 \%$ sodium and $0.24 \%$ magnesium (Changsha Tianqin Biotechnology Co., Ltd., Changsha, China). Classification of rats as hypercalciuric was performed at the time of weaning. The genetic hypercalciuric rats were defined as those with urine Ca excretion $>1.5 \mathrm{mg} / 24 \mathrm{~h}$ on two successive $24 \mathrm{~h}$ urine collections. The male and female rats with the highest levels of $\mathrm{Ca}$ excretion were screened and matched to propagate the colony. The male hypercalciuric rats from generation 23, with a body weight between 180 and $220 \mathrm{~g}$ were used in the present study. All animal procedures were approved by the Animal Care Committees of Huazhong University of Science and Technology University.

Primary renal tubular epithelial cells (RTECs). The rats were anesthetized with an intraperitoneal injection into the abdominal cavity of $3 \%$ pentobarbital sodium (Beijing Propbs Biotechnology Co., Ltd, Beijing, China). The kidneys were removed from the rats, following ligation of the renal pedicle vessels. The average length and width of the kidneys were $17.58 \pm 0.82 \mathrm{~mm}$ and $8.01 \pm 0.92 \mathrm{~mm}$, respectively. Primary RTECs (PriCell Research Institute, Wuhan, China) were isolated from the genetic hypercalciuric rat kidneys and identified by an evaluation for tetramethylrhodamine-marked E-cadherin (Wuhan Amyjet Scientific Co., Ltd., Wuhan, China) (Fig. 1A). All cells were maintained in Dulbecco's modified Eagle's medium (DMEM) (PriCell, China) supplemented with $10 \%$ fetal bovine serum, and were incubated in a humidified atmosphere containing $5 \% \mathrm{CO}_{2}$ at $37^{\circ} \mathrm{C}$. The third generation of RTECs were used for the subsequent experiments.

Tetramethylrhodamine staining. Coverslips were placed onto a 12-well plate and cells were grown in culture media until they reached $50 \%$ confluence. The media was aspirated from the plates and washed twice with phosphate-buffered saline (PBS). The cells were fixed with $4 \%$ paraformaldehyde solubilized in PBS-0.1\% Triton X-100 for $20 \mathrm{~min}$ at room temperature. The cells were then blocked for $1 \mathrm{~h}$ with $2 \mathrm{ml} 1 \mathrm{X}$ PBS-1\%/bovine serum albumin-4\%. They were then washed twice for $5 \mathrm{~min}$ with $2 \mathrm{ml}$ 1X PBS. Diluted primary antibody (rabbit anti-rat E cadherin antibody; $30 \mu \mathrm{l}$ ) was added to each well and incubated at $37^{\circ} \mathrm{C}$ for $30 \mathrm{~min}$. Diluted secondary antibody (tetramethylrhodamine marked goat anti-rabbit $\mathrm{IgG}$; $30 \mu \mathrm{l}$ ) was then added to each well and incubated at $37^{\circ} \mathrm{C}$ for $30 \mathrm{~min}$. The cover glass was removed and washed five times for $5 \mathrm{~min}$ in $45^{\circ} \mathrm{C}$ washing solution at room temperature.

Lentiviral vectors. A lentiviral vector containing small hairpin (sh)RNA specifically targeting rat VDR, to silence the gene, was constructed by Genechem Co. Ltd (Shanghai, China), and classified as Lenti-VDR-sh. The targeting sequence of the shRNA, as described previously, was 5'-TGACCAGATTGTC
CTGCTTAA-3' (9). As a control, a negative control (nc) vector (Genechem, Shanghai, China) was used, termed Lenti-VDR-nc. These two lentiviral expression vectors contained the reporter gene of green fluorescent protein (GFP). The lentiviral stocks were stored in small aliquots $(50 \mu \mathrm{l})$ at $-80^{\circ} \mathrm{C}$ for titration and cell infection. The prepared RTECs were transfected with either Lenti-VDR-sh or Lenti-VDR-nc. The cells were transfected with Lenti-VDR-sh at $1 \times 10^{6} \mathrm{TU} / \mathrm{ml}$ at $37^{\circ} \mathrm{C}$, and harvested at $0,6,12,24,48$ and $96 \mathrm{~h}$ post-transfection. The transfection efficiency was detected directly by assessing the expression ratio of GFP by fluorescence microscopy (TE2000U; Nikon Corporation, Tokyo, Japan).

\section{Experiment procedures}

Experiment one. The RTECs were seeded into six-well plates at a density of $2 \times 10^{5}$ cells/well. In group 1, the RTECs were treated with normal saline (NS) as a control. In group 2, the cells were transduced with Lenti-VDR-sh at $1 \times 10^{6} \mathrm{TU} / \mathrm{ml}$ at $37^{\circ} \mathrm{C}$. As a negative control, the cells were incubated with Lenti-VDR-nc and classified as group 3. The cells were harvested following $0,6,12,24,48$ and $96 \mathrm{~h}$ of infection, and cells expressing green fluorescence were identified using a fluorescence microscope (Fig. 1B). The gene and protein levels of BMP2, Runx 2 and Osterix were detected using reverse-transcription-quantitative polymerase chain reaction (RT-qPCR) and western blot assays, respectively.

Experiment two. The RTECs were seeded into six-well plates at a density of $5 \times 10^{5}$ cells per well. The cells were cultured with $10^{-8} \mathrm{~mol} / 1 \mathrm{1}, 25(\mathrm{OH})_{2} \mathrm{D}_{3}$ at room temperature, and harvested following $0,6,12,24,48$ and $96 \mathrm{~h}$ of treatment. Using an o-cresolphthalein complexone method, the calcium levels in the primary RTECs were measured.

Experiment three. The RTECs were cultured with NS or calcium in $\mathrm{Ca}^{2+}-1\left(10^{-10} \mathrm{~mol} / \mathrm{l}\right), \mathrm{Ca}^{2+}-2\left(10^{-9} \mathrm{~mol} / \mathrm{l}\right), \mathrm{Ca}^{2+}-3$ $\left(10^{-8} \mathrm{~mol} / \mathrm{l}\right)$ or $\mathrm{Ca}^{2+}-4\left(10^{-7} \mathrm{~mol} / \mathrm{l}\right)$, and harvested following 0 , 12,24 and $48 \mathrm{~h}$, respectively. The cells were collected after 0 , 12, 24 and $48 \mathrm{~h}$, respectively. The gene and protein levels of BMP2, Runx2 and Osterix were detected using RT-qPCR and western blot assays, respectively.

$R T-q P C R$ analysis. Total RNA was isolated from the primary RTECs using TRIzol Reagent (Invitrogen Life Technologies, Carlsbad, CA, USA), according to the manufacturer's instructions. The cDNA synthesis ( $2 \mu \mathrm{g}$ of total RNA) was performed using oligod (T) primer and Moloney Murine Leukemia Virus reverse transcriptase (Takara Bio, Inc., Shiga, Japan), according to the manufacturer's instructions. The mRNA levels of BMP2, Runx2, Osterix and the housekeeping gene, $\beta$-actin, were analyzed by qPCR on a Light Cycler Real Time PCR system (Roche Diagnostics, Basel, Switzerland). The qPCR reactions were performed using SYBR Green PCR Master mix (Takara Bio, Inc). Thermocycling was performed at a final volume of $20 \mu \mathrm{l}$, which contained $2 \mu \mathrm{l} \mathrm{cDNA}$ and $400 \mathrm{nM}$ of each of the forward and reverse primers. The qPCR reaction was performed using the following program: $95^{\circ} \mathrm{C}$ for $10 \mathrm{~min}$, 40 cycles of $95^{\circ} \mathrm{C}$ for $30 \mathrm{sec}, 60^{\circ} \mathrm{C}$ for $30 \mathrm{sec}$, and $72^{\circ} \mathrm{C}$ for $30 \mathrm{sec}$. The primer sequences of BMP2, Runx2, Osterix and $\beta$-actin are described in Table I. The threshold cycle $(\mathrm{Ct})$ values 
Table I. Sequences of the rat primers used for reverse transcription-quantitative polymerase chain reaction.

\begin{tabular}{lccc}
\hline Gene & Forward primer & Reverse primer & Primer length (bp) \\
\hline BMP2 & 5'-ACCAGACTATTGGACACCAG-3' & 5'-AATCCTCACATGTCTCTTGG-3' & 237 \\
Runx2 & 5'-TCCCATCTGCTAGAAGTGTT-3' & 5'-TTAGCCAGCTCACTTTCTTC-3' & 202 \\
Osterix & 5'-AAGCCATACACTGACCTTTC-3' & 5'-GTGGGTAGTCATTGGCATAG-3' & 191 \\
$\beta$-actin & 5'-AAGAGCTATGAGCTGCCTGA-3' & 5'-TACGGATGTCAACGTCACAC-3' & 159 \\
\hline
\end{tabular}

BMP2, bone morphogenetic protein 2; Runx2, runt-related transcription factor 2.

A

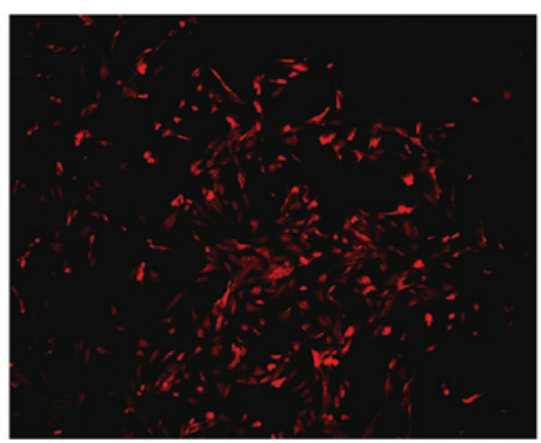

C

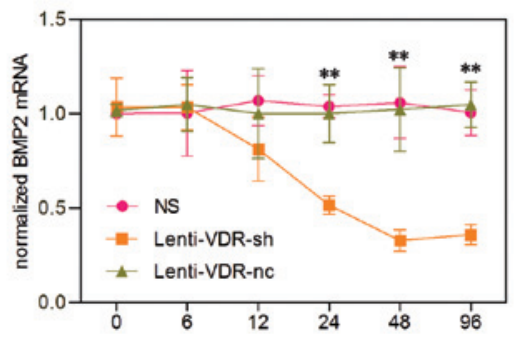

$\mathbf{E}$

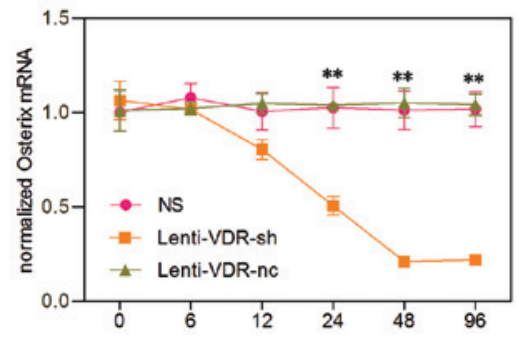

B

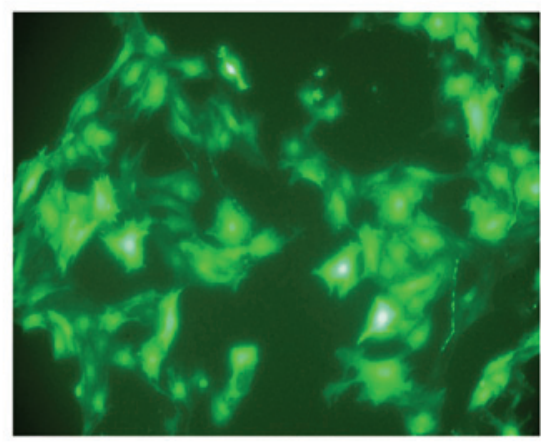

D
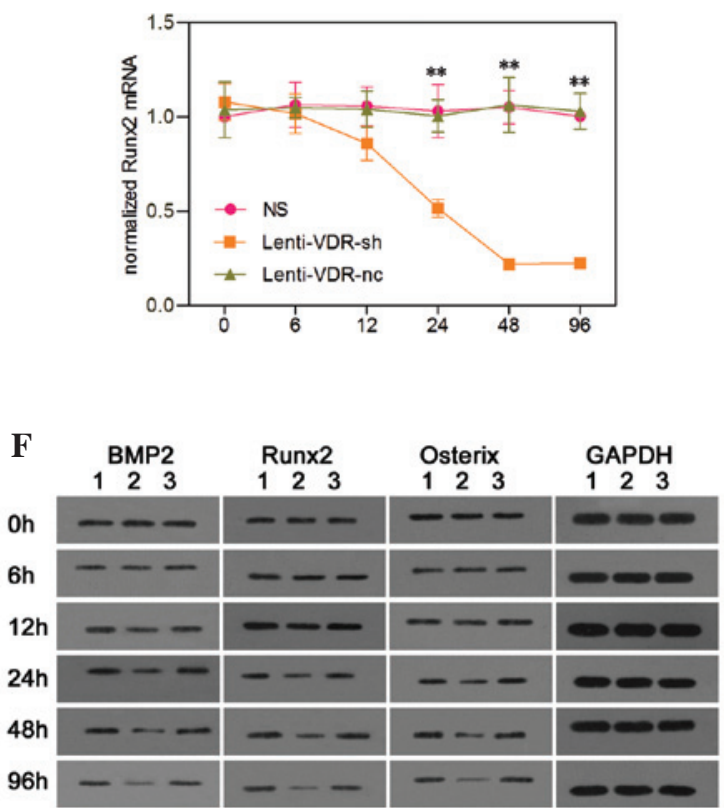

Figure 1. Effect of VDR depletion on the expression levels of osteogenic factors in primary RTECs. (A) Expression of E-cadherin in RTECs, stained using tetramethylrhodamine (magnification, x100). (B) Identification of the RTEC-infected lentivirus vector (magnification, x100). Using reverse transcription-quantitative polymerase chain reaction, the mRNA expression levels of (C) BMP2, (D) Runx2 and (E) Osterix were measured in the NS, Lenti-VDR-sh and Lenti-VDR-nc groups at different time-points. The expression was normalized to that of the $\beta$-actin gene for each sample. Data are expressed as the mean \pm standard deviation. ${ }^{* *} \mathrm{P}<0.01$ vs. NS. (F) Western blot analysis was performed to determine the protein expression levels of BMP2, Runx 2 and Osterix in the NS, Lenti-VDR-sh and Lenti-VDR-nc groups at different time-points after treatment. The expression level of GAPDH was determined to ensure equal loading. Lane 1: NS, lane 2: Lenti-VDR-sh, lane 3: Lenti-VDR-nc. RTEC, renal tubular epithelial cell; VDR, vitamin D receptor; BMP2, bone morphogenetic protein 2; Runx2, runt-related transcription factor 2; NS, normal saline nc, negative control.

were analyzed using the comparative $\mathrm{Ct}\left({ }^{\Delta \Delta \mathrm{Ct}}\right)$ method $(10)$ and normalized to the endogenous control, $\beta$-actin. Fold changes were calculated using the $2^{-\Delta \Delta \mathrm{Ct}}$ method.
Western blot analysis. The total proteins $(50 \mu \mathrm{g})$ harvested from each sample were separated by $12 \%$ SDS-PAGE (Shenzhen Qi Hong Yuan Technology Co., Ltd., Shenzhen, China) 
and transferred onto polyvinylidene difluoride membranes (Millipore, Bedford, USA). Nonspecific reactivity was blocked using 5\% nonfat dry milk in Tris-buffered saline with Tween 20 (TBST; Shanghai Shifeng Biotechnology, Co., Ltd., Shanghai, China) for $2 \mathrm{~h}$ at $22^{\circ} \mathrm{C}$. The membrane was then incubated with goat polyclonal BMP2 antibody (cat. no. SC-6895; 1:500; Santa Cruz Biotechnology, Inc., Dallas, TX, USA), goat polyclonal Runx2 antibody (cat. no. SC-8566; 1:400; Santa Cruz Biotechnology, Inc.) or goat polyclonal Osterix antibody (cat. no. SC-22538 1:400; Santa Cruz Biotechnology, Inc.) overnight at $4{ }^{\circ} \mathrm{C}$, followed by reaction with horseradish peroxidase-conjugated goat anti-mouse or rabbit anti-goat antibody (cat. nos. BA1050 and BA1060; 1:40,000 or 1:50,000; Boster Systems, Inc., Pleasanton, CA, USA) for $2 \mathrm{~h}$ at $22^{\circ} \mathrm{C}$. The reactive protein was detected using an enhanced chemiluminescence system (GE Healthcare, Amersham, UK).

Quantification of calcium deposition. The cells were decalcified using 0.6 N HCl (Shenzhen Qihongyuan Technology Co., Ltd., Shenzhen, China) for $24 \mathrm{~h}$. The calcium content of the $\mathrm{HCl}$ supernatants were determined colorimetrically using the o-cresolphthalein complexone method (Calcium kit; Sigma-Aldrich, St. Louis, MO, USA), as previously described (10). Following decalcification using $0.6 \mathrm{~N} \mathrm{HCl}$ for $24 \mathrm{~h}$, the cells were washed three times with PBS and solubilized with $0.1 \mathrm{~N} \mathrm{NaOH} / 0.1 \%$ SDS. The protein content was measured using a Bicinchoninic Acid Protein Assay kit (Pierce Biotechnology, Inc., Rockford, IL, USA). The calcium content of the cell layer was normalized to the protein content.

Statistical analysis. The data were analyzed using Statistical Package for Social Science (SPSS) 10.0 (SPSS, Inc., Chicago, IL, USA). The values are expressed as the mean \pm standard deviation. Unpaired Student's t-tests (two-tailed) were used to compare the means between two independent groups/samples. General linear models (GLM) for repeated measures were used for comparisons over time. If the global tests from the GLM were significant, Bonferroni's tests were used for pairwise comparisons. Multiple comparisons between experimental groups were performed on the data obtained from three independent experiments using one-way analysis of variance (ANOVA) followed by Bonferroni's post-hoc test. $\mathrm{P}<0.05$ was considered to indicate a statistically significant difference.

\section{Results}

Effect of VDR knockdown on the expression of osteogenic factors in primary RTECs. As shown in Fig. 1, no significant differences were detected in mRNA expression levels of BMP2, Runx 2 or Osterix among the NS, Lenti-VDR-sh and Lenti-VDR-nc groups at the beginning of the experiment (0 h). However, 24, 48 and $96 \mathrm{~h}$ after infection, the mRNA expression levels of BMP2, Runx2 and Osterix were markedly decreased in the Lenti-VDR-sh group compared with the NS and Lenti-VDR-nc groups, and in the latter less than in the former. By contrast, no significant differences were identified in the mRNA expressionu levels of BMP2, Runx2 and Osterix between the NS and Lenti-VDR-nc groups. At
A

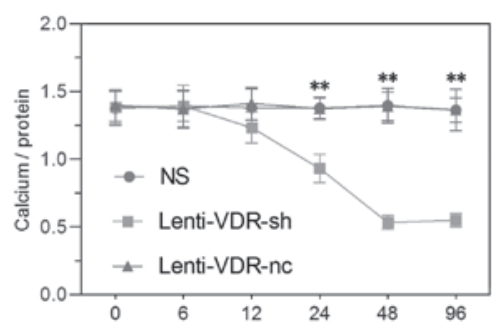

B

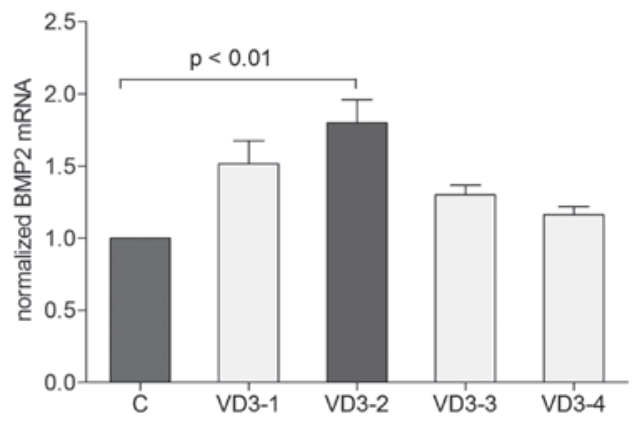

C

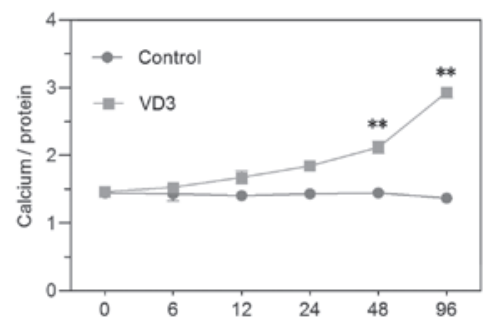

Figure 2. Effect of silencing the VDR gene and increased $1,25(\mathrm{OH})_{2} \mathrm{D}_{3}$ on calcium levels in primary RTECs. Primary RTECs were treated with NS, Lenti-VDR-sh or Lenti-VDR-nc and harvested 0, 6, 12, 24, 48 and $96 \mathrm{~h}$ after treatment. (A) Calcium levels in the RTECs were determined colorimetrically using the o-cresolphthalein complexone method. Calcium content was normalized to the protein content (calcium/protein). ${ }^{* *} \mathrm{P}<0.01$ vs. NS. (B) RTECs were cultured for the indicated durations with $\mathrm{NS}, \mathrm{VD}_{3}-1\left(10^{-7} \mathrm{~mol} / \mathrm{l}\right), \mathrm{VD}_{3}-2$ $\left(10^{-8} \mathrm{~mol} / \mathrm{l}\right), \mathrm{VD}_{3}-3\left(10^{-9} \mathrm{~mol} / \mathrm{l}\right)$ or $\mathrm{VD}_{3}-4\left(10^{-10} \mathrm{~mol} / \mathrm{l}\right)$, and the mRNA expression of BMP2 was examined by reverse transcription-quantitative polymerase chain reaction. (C) RTECs were cultured in the presence of the $10^{-8} \mathrm{~mol} / 11,25(\mathrm{OH})_{2} \mathrm{D}_{3}$ and were harvested at different time-points. The calcium levels in the primary RTECs were determined using the o-cresolphthalein complexone method. ${ }^{* * *} \mathrm{P}<0.01$ vs. Control. Data are expressed as the mean \pm standard deviation. RTEC, renal tubular epithelial cell; VDR, vitamin D receptor; BMP2, bone morphogenetic protein 2; NS, normal saline (Control; C); VD3, $1,25(\mathrm{OH})_{2} \mathrm{D}_{3}$.

$12 \mathrm{~h}$, the expression levels of BMP2, Runx2 and Osterix appeared to be lower in the Lenti-VDR-sh group compared with the NS and Lenti-VDR-nc groups, however, no significant differences were observed among the NS, Lenti-VDR-sh and Lenti-VDR-nc groups. The lowest mRNA level was observed at 48 and $96 \mathrm{~h}$ in the Lenti-VDR-sh group, with no significant change observed between these two time points.

The western blot analysis revealed similar change in protein expression levels as those observed in the mRNA expression levels following silencing of the VDR gene in the primary RTECs. As shown in Fig. 1, the protein levels of osteogenic factors were markedly decreased at 24, 48 and $96 \mathrm{~h}$ in the Lenti-VDR-sh group (lane 2). Conversely, the protein levels of BMP2, Runx2 and Osterix were not altered 
A

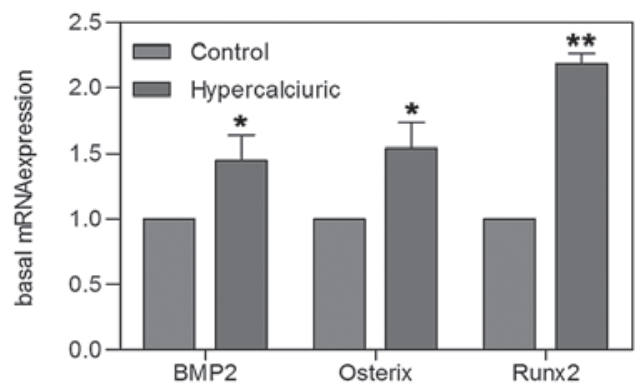

C

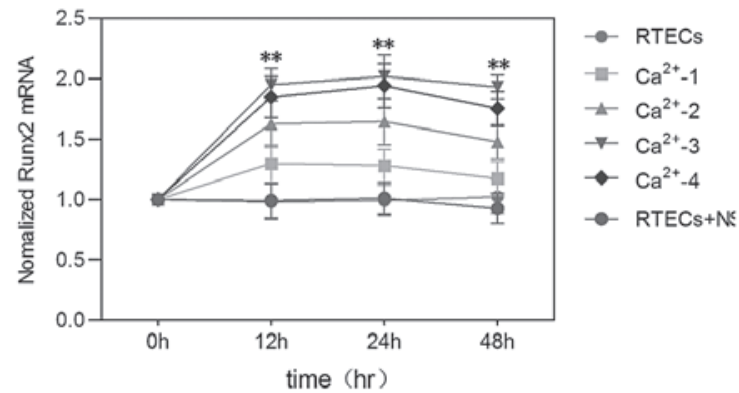

E

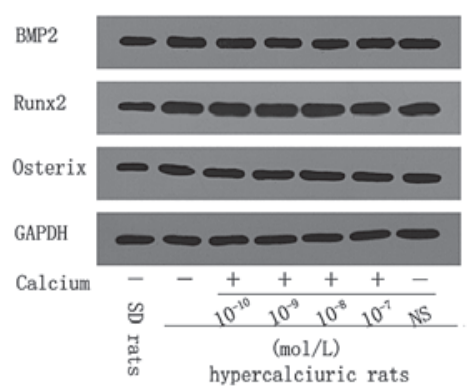

G

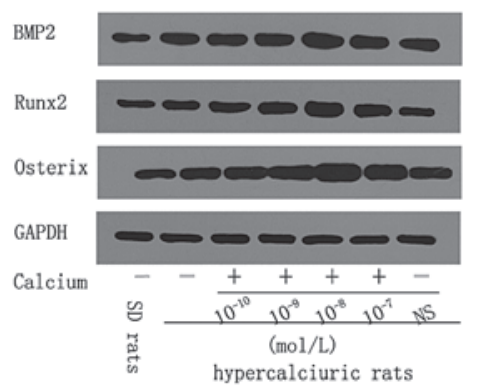

B

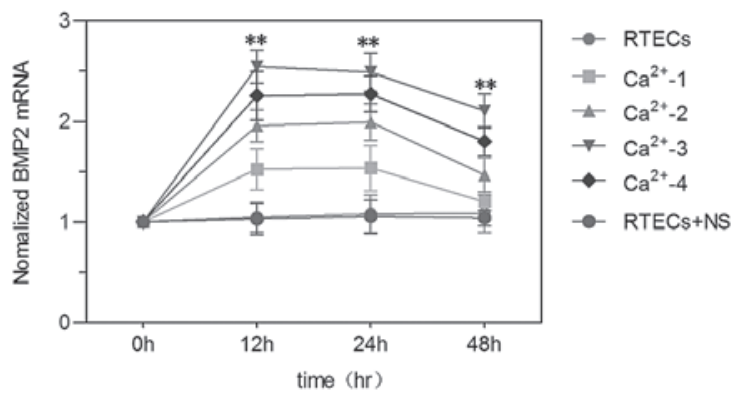

D

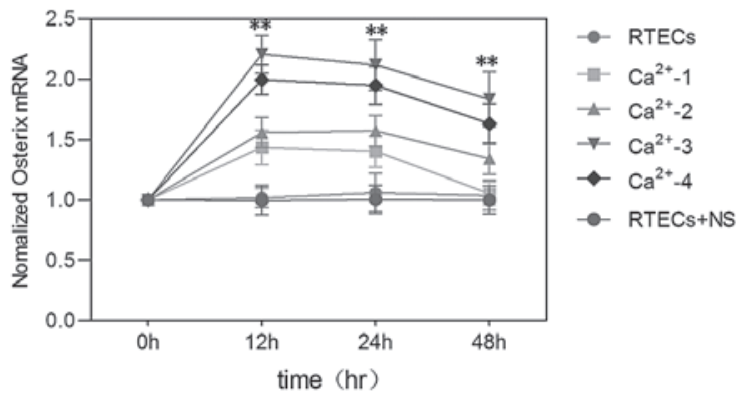

$\mathbf{F}$

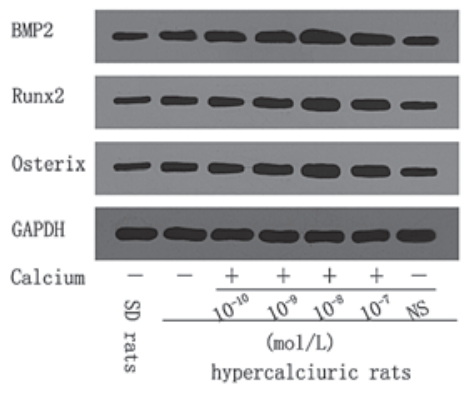

H

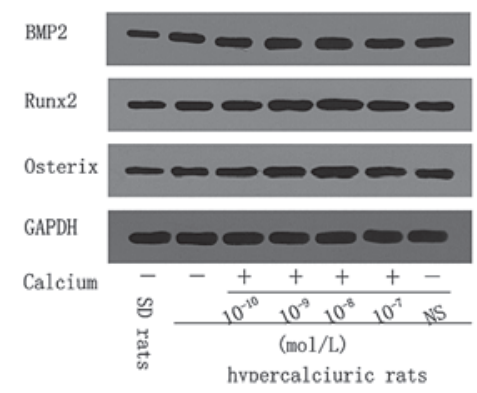

Figure 3. Effect of elevated calcium on the expression of osteogenic factors in primary RTECs. (A) Basal mRNA expression levels of the BMP2, Runx2 and Osterix osteogenic factors were detected in cells from SD and genetic hypercalciuric rats. ${ }^{*} \mathrm{P}<0.05,{ }^{* *} \mathrm{P}<0.01$ vs. Control. (B) RTECs were cultured for the indicated time-periods with $\mathrm{Ca}^{2+}-1\left(10^{-10} \mathrm{~mol} / \mathrm{L}\right), \mathrm{Ca}^{2+}-2\left(10^{-9} \mathrm{~mol} / \mathrm{L}\right), \mathrm{Ca}^{2+}-3\left(10^{-8} \mathrm{~mol} / \mathrm{L}\right), \mathrm{Ca}^{2+}-4\left(10^{-7} \mathrm{~mol} / \mathrm{L}\right)$ or NS . Using reverse transcription-quantitative polymerase chain reaction, the mRNA levels of (B) BMP2, (C) Runx2 and (D) Osterix were measured at different time-points and normalized to the expression of $\beta$-actin for each sample. Data are expressed as the mean \pm standard deviation $\left({ }^{* *} \mathrm{P}<0.01\right.$, vs. RTECs). The protein expression levels of BMP2, Runx 2 and Osterix were determined at (E) $0,(\mathrm{~F}) 12,(\mathrm{G}) 24$ and $(\mathrm{H}) 48 \mathrm{~h}$ by western blot analysis. The expression of GAPDH was measured to ensure equal loading. RTEC, renal tubular epithelial cell; BMP2, bone morphogenetic protein 2; Runx2, runt-related transcription factor 2; NS, normal saline; SD, Sprague Dawley.

following treatment in the NS or Lenti-VDR-nc groups (lanes 1 and 3).

Effect of VDR depletion on calcium deposition in primary RTECs. The quantities of calcium deposition in primary RTECs was determined colorimetrically using the o-cresolphthalein complex one method, as previously described (11).
As shown in Fig. 2, no significant differences were identified in calcium deposition in the primary RTECs among the NS, Lenti-VDR-sh or Lenti-VDR-nc groups at the beginning of experiment. A decrease in the calcium content of the primary RTECs was observed as early as $12 \mathrm{~h}$ following exposure to Lenti-VDR-sh, and the lowest level was observed at $48 \mathrm{~h}$. However, the total levels of calcium deposition in the cells in 
the NS and Lenti-VDR-nc groups were unchanged during the experiment.

Effect of elevated $1,25(\mathrm{OH})_{2} \mathrm{D}_{3}$ on calcium levels in primary RTECs. The RTECs were cultured for the indicated time-periods in the NS (control), $\mathrm{VD}_{3}-1\left(10^{-7} \mathrm{~mol} / \mathrm{l}\right), \mathrm{VD}_{3}-2$ $\left(10^{-8} \mathrm{~mol} / \mathrm{l}\right), \mathrm{VD}_{3}-3\left(10^{-9} \mathrm{~mol} / \mathrm{l}\right)$ and $\mathrm{VD}_{3}-4\left(10^{-10} \mathrm{~mol} / \mathrm{l}\right)$ groups As shown in Fig. 2, 1,25(OH) $)_{2} \mathrm{D}_{3}$ at $10-8 \mathrm{~mol} / \mathrm{l}$ had the highest efficiency in primary RTECs, determined by RT-qPCR $(\mathrm{P}<0.01)$. To determine the association between $1,25(\mathrm{OH})_{2} \mathrm{D}_{3}$ and RTEC mineralization, the levels of calcium were examined in primary RTECs treated with $1,25(\mathrm{OH})_{2} \mathrm{D}_{3}$. As shown in Fig. 2, treatment of primary RTECs with $1,25(\mathrm{OH})_{2} \mathrm{D}_{3}$ caused time-dependent upregulation of calcium levels, and upregulated calcium levels by 2.14 -fold at $96 \mathrm{~h}$.

Effect of elevated calcium on the expression of osteogenic factors in primary RTECs. The basal levels of osteogenic factors were detected in cells in the genetic hypercalciuric and $\mathrm{NC}$ rats. The mRNA and protein expression levels of BMP2, Runx2 and Osterix in the cells were significantly higher in the genetic hypercalciuric rats compared with the NC rats $\left({ }^{* *} \mathrm{P}<0.01\right.$; Fig. 3).

The mRNA expression levels of BMP2, Runx2 and Osterix were significantly increased in the cells incubated with calcium. The cells were then cultured for the indicated time-periods in $\mathrm{Ca}^{2+}-1\left(10^{-10} \mathrm{~mol} / \mathrm{l}\right), \mathrm{Ca}^{2+}-2\left(10^{-9} \mathrm{~mol} / \mathrm{l}\right), \mathrm{Ca}^{2+}-3$ $\left(10^{-8} \mathrm{~mol} / \mathrm{l}\right)$ and $\mathrm{Ca}^{2+}-4\left(10^{-7} \mathrm{~mol} / \mathrm{l}\right)$. As shown in Fig. 3 , the levels of calcium at 10-8 mol/l exhibited the highest efficiency in the primary RTECs, determined by RT-qPCR. After 12, 24 and $48 \mathrm{~h}$, the mRNA expression levels of BMP2, Runx2 and Osterix were markedly increased in the cells incubated with calcium compared with the cells treated with NS and the untreated cells. Western blot analysis demonstrated that the changes protein expression levels were similar to those observed in mRNA expression levels following the upregulation of calcium in the primary RTECs (Fig. 3).

\section{Discussion}

Evidence for an association between nephrolithiasis and certain cardiovascular diseases has been provided by epidemiological studies (12-14). Over a century ago, pathologists recognized atherosclerotic calcification as a form of extraskeletal ossification (15). It has since been demonstated that vascular calcification is not passive, but is a complex, active and highly regulated process of ectopic calcification (16-18). This process involves numerous regulating factors and appears to share several similarities with skeletal mineralization and osteogenesis (19). BMPs, which belong to the transforming growth factor- $\beta$ (TGF- $\beta$ ) superfamily, induce bone and cartilage formation when implanted at ectopic sites in rats $(20,21)$. Among BMPs, BMP2, a potent osteogenic differentiation factors, is required for osteoblast differentiation and bone formation and has been implicated in vascular calcification (22).

The BMP2 signaling pathway contains BMP2, Runx2 and Osterix. Li (22) demonstrated that BMP2, acting through Runx2, induces ectopic ossification in muscle tissue in vivo. Runx 2 regulates osteoblast differentiation and chondrocyte maturation and is an essential regulator of calcification of VSMCs in vitro (23). Matsubara (24) observed that BMP2 regulates Osterix through Msh homeobox 2 (Msx2) and Runx 2 during osteoblast differentiation. Osterix is a zinc finger-containing transcription factor and is expressed in all developing bones (25). It has been demonstrated that Osterix, which directs the differentiation of pre-osteoblasts into mature osteoblasts, lies downstream of Runx2 $(25,26)$. However, whether the BMP2 signaling pathway is involved in kidney stone formation remains to be elucidated. In our previous study, the expression levels of BMP2, Runx2 and Osterix were found to be increased in genetic hypercalciuric rat kidney tissue (9). In the present study, higher expression levels of BMP2, Runx 2 and Osterix were also observed in primary RTECs. The high expression levels of these osteogenic factors indicated that kidney stone formation may proceed in the same way as occurs in bone formation and ectopic calcification in arteries.

However, high expression levels of VDR in the duodenum and kidney is also observed in genetic hypercalciuric rats $(7,8)$. The association between VDR and the osteogenic factors remains to be fully elucidated. The active form of vitamin $\mathrm{D}$, $1,25(\mathrm{OH})_{2} \mathrm{D}_{3}$, exerts its biological actions through binding to the VDR. Zebger-Gong (27) provided evidence that high-dose $1,25(\mathrm{OH})_{2} \mathrm{D}_{3}$ (calcitriol) increased the expression of Osterix and induced an osteoblastic phenotype in VSMCs, in subtotally nephrectomized rats and in vitro. However, serum levels of $1,25(\mathrm{OH})_{2} \mathrm{D}$ are not elevated and, therefore, elevated levels of tissue VDR may amplify the biological actions of normal circulating $1,25(\mathrm{OH})_{2} \mathrm{D}$ levels on stone formation $(7,28)$. Our previous study also revealed that elevated $1,25(\mathrm{OH})_{2} \mathrm{D}_{3}$ induced an increase in the mRNA and protein levels of BMP2, Runx2 and Osterix in primary RTECs (9). In the present study, VDR knockdown caused a significant decrease in the gene and protein levels of BMP2, Runx2, and Osterix in primary RTECs. These results indicated that $1,25(\mathrm{OH})_{2} \mathrm{D}_{3} / \mathrm{VDR}$ positively regulated the expression of BMP2, Runx 2 and Osterix in vitro. However, how $1,25(\mathrm{OH})_{2} \mathrm{D}_{3} / \mathrm{VDR}$ increases the expression of these osteogenic factors remains to be elucidated.

Hypercalciuria is the most important characteristic of genetic hypercalciuric rats. In the present study, the calcium deposition in primary RTECs were reduced following silencing of the VDR gene. Elevated levels of $1,25(\mathrm{OH})_{2} \mathrm{D}_{3}$ caused a time-dependent upregulation of calcium levels in the primary RTECs, but not in the control rats. These results suggested that genetic hypercalciuric rats may be more susceptible to elevated levels of $1,25(\mathrm{OH})_{2} \mathrm{D}_{3}$ compared with control rats. However, Schmidt (29) reported that calcified areas and the expression levels of Msx2, BMP2 and Runx2 in the blood vessels in VDR-knockout mice are increased compared with wild-type mice. This suggests that the action of VDR on the expression of osteoblastic differentiation factors differs in kidney and blood vessels.

In the present study, the BMP2 singling pathway and the deposition of calcium in primary RTECs was regulated by VDR. However, a significant gap remains in current understanding of the BMP2 singling pathway and calcium deposition in primary RTECs. In the present study, the gene and protein levels of BMP2, Runx 2 and Osterix were increased in the RTECs cultured with different concentrations of $\mathrm{Ca}^{2+}$, 
which reveals that $\mathrm{Ca}^{2+}$ may be more important in stone formation. It ws $\mathrm{Ca}^{2+}$, rather than $1,25(\mathrm{OH})_{2} \mathrm{D}_{3} / \mathrm{VDR}$, that caused RTECs to express more osteogenic factors directly, however, $1,25(\mathrm{OH})_{2} \mathrm{D}_{3} / \mathrm{VDR}$ may provide renal tubular epithelial cells with high calcium environment by negatively regulating the expression of renal epithelial calcium transport proteins involving transient receptor potential cation channel subfamily $\mathrm{V}$ member 5(8). These appear to explain the mechanisms underlying the contribution of elevated VDR levels to higher expressions of these osteogenic factors.

In conclusion, the findings of the present study indicated that osteogenic factors, including BMP2, Runx2 and Osterix may be important role in renal stone formation in IH. VDR knockdown reduced the expression levels of BMP2, Runx2 and Osterix, and decreased the calcium content of primary RTECs. However, elevated $1,25(\mathrm{OH})_{2} \mathrm{D}_{3} / \mathrm{VDR}$ induced an increase in calcium content in the primary RTECs, and elevated calcium levels increased the expression levels of BMP2, Runx2 and Osterix. Therefore, $1,25(\mathrm{OH})_{2} \mathrm{D}_{3} / \mathrm{VDR}$ may mediate the increases in the expression of BMP2, Runx 2 and Osterix by positively regulating calcium levels in primary RTECs.

\section{Acknowledgements}

This study was supported by grants from the National Science Foundation of China (nos. 30972985 and 81270787).

\section{References}

1. Relan V, Khullar M, Singh SK and Sharma SK: Association of vitamin D receptor genotypes with calcium excretion in nephrolithiatic subjects in northern India. Urol Res 32: 236-240, 2004.

2. Favus MJ, Karnauskas AJ, Parks JH and Coe FL: Peripheral blood monocyte vitamin $\mathrm{D}$ receptor levels are elevated in patients with idiopathic hypercalciuria. J Clin Endocrinol Metab 89: 4937-4943, 2004.

3. Burton DG, Matsubara H and Ikeda K: Pathophysiology of vascular calcification: Pivotal role of cellular senescence in vascular smooth muscle cells. Exp Gerontol 45: 819-824, 2010.

4. Kanno Y, Into T, Lowenstein CJ and Matsushita K: Nitric oxide regulates vascular calcification by interfering with TGFsignalling. Cardiovasc Res 77: 221-230, 2008.

5. Jang WG, Kim EJ, Kim DK, et al: BMP2 protein regulates osteocalcin expression via Runx2-mediated Atf6 gene transcription. J Biol Chem 287: 905-915, 2012

6. Cai J, Pardali E, Sanchez-Duffhues G and ten Dijke P: BMP signaling in vascular diseases. FEBS Lett 586: 1993-2002, 2012

7. Wang SG, Luo DX and Liu JH: Establishment of genetic hypercalciuric stone-forming rat's model. Chin J Urol 27: 63-65, 2006.

8. Xi QL, Wang SG, Ye ZQ, et al: Effect of silencing VDR gene in kidney on renal epithelial calcium transporter proteins and urinary calcium excretion in genetic hypercalciuric stone-forming rats. Urology 78: 1442. e1-e7, 2011.
9. Jia Z, Wang S, Tang J, et al: Does crystal deposition in genetic hypercalciuric rat kidney tissue share similarities with bone formation? Urology 83: 509. e7-e14, 2014.

10. Schmittgen TD and Livak KJ: Analyzing real-time PCR data by comparative C(T) method. Nat Protoc 3: 1101-1108, 2008.

11. Jono S, McKee MD, Murry CE, et al: Phosphate regulation of vascular smooth muscle cell calcification. Circ Res 87: E10-E17, 2000

12. Khan SR: Is oxidative stress, a link between nephrolithiasis and obesity, hypertension, diabetes, chronic kidney disease, metabolic syndrome? Urol Res 40: 95-112, 2012.

13. Hayden MR, Tyagi SC, Kolb L, Sowers JR and Khanna R: Vascular ossification-calcification in metabolic syndrome, type 2 diabetes mellitus, chronic kidney disease, and calciphylaxis-calcific uremic arteriolopathy: The emerging role of sodium thiosulfate. Cardiovasc Diabetol 4: 4, 2005.

14. Sage AP, Tintut Y and Demer LL: Regulatory mechanisms in vascular calcification. Nat Rev Cardiol 7: 528-536, 2010.

15. Bunting $\mathrm{CH}$ : The formation of true bone with cellular (red) marrow in a sclerotic aorta. J Exp Med 8: 365-376, 1906.

16. Shao JS, Aly ZA, Lai CF, et al: Vascular Bmp Msx2 Wnt signaling and oxidative stress in arterial calcification. Ann NY Acad Sci 1117: 40-50, 2007.

17. Moe SM and Chen NX: Mechanisms of vascular calcification in chronic kidney disease. J Am Soc Nephrol 19: 213-216, 2008.

18. Schoppet M, Shroff RC, Hofbauer LC and Shanahan CM: Exploring the biology of vascular calcification in chronic kidney disease: what's circulating? Kidney Int 73: 384-390, 2008.

19. Boström K, Watson KE, Horn S, Wortham C, Herman IM and Demer LL: Bone morphogenetic protein expression in human atherosclerotic lesions. J Clin Invest 91: 1800-1809, 1993.

20. Reddi AH: Bone morphogenetic proteins: an unconventional approach to isolation of first mammalian morphogens. Cytokine Growth Factor Rev 8: 11-20, 1997.

21. Wozney JM, Rosen V, Celeste AJ, et al: Novel regulators of bone formation: molecular clones and activities. Science 242: 1528-1534, 1988.

22. Li X, Yang HY and Giachelli CM: BMP-2 promotes phosphate uptake, phenotypic modulation and calcification of human vascular smooth muscle cells. Atherosclerosis 199: 271-277, 2008

23. Sun Y, Byon CH, Yuan K, et al: Smooth muscle cell-specific runx2 deficiency inhibits vascular calcification. Circ Res 111: 543-552, 2012.

24. Matsubara T, Kida K, Yamaguchi A, et al: BMP2 regulates Osterix through Msx2 and Runx2 during osteoblast differentiation. J Biol Chem 283: 29119-29125, 2008.

25. Nakashima K, Zhou X, Kunkel G, et al: The novel zinc finger-containing transcription factor osterix is required for osteoblast differentiation and bone formation. Cell 108: 17-29, 2002.

26. Komori T: Regulation of osteoblast differentiation by transcription factors. J Cell Biochem 99: 1233-1239, 2006.

27. Zebger-Gong H, Muller D, Diercke M, et al: 1,25-Dihydroxyvitamin D3-induced aortic calcifications in experimental uremia: up-regulation of osteoblast markers, calcium-transporting proteins and osterix. J Hypertens 29: 339-348, 2011.

28. Bai S, Wang H, Shen J, Zhou R, Bushinsky DA and Favus MJ: Elevated vitamin D receptor levels in genetic hypercalciuric stone-forming rats are associated with downregulation of Snail. J Bone Miner Res 25: 830-840, 2010.

29. Schmidt N, Brandsch C, Kühne H, Thiele A, Hirche F and Stangl GI: Vitamin D receptor deficiency and low vitamin D diet stimulate aortic calcification and osteogenic key factor expression in mice. PLoS One 7: e35316, 2012. 